\title{
Exploring the Characteristics of Information Systems Maintenance: Defining Focus and Content through Objects
}

\author{
Malin Nordström, Karin Axelsson and Ulf Melin
}

\section{Linköping University Post Print}

\section{Tweet}

N.B.: When citing this work, cite the original article.

Original Publication:

Malin Nordström, Karin Axelsson and Ulf Melin, Exploring the Characteristics of Information Systems Maintenance: Defining Focus and Content through Objects, 2011, Nordic Contributions in IS Research: Second Scandinavian Conference, on Information Systems, SCIS 2011, Turku, Finland, August 16-19, 2011. Proceedings, 112-123. http://dx.doi.org/10.1007/978-3-642-22766-0_11

Copyright: Springer-Verlag Berlin Heidelberg

Postprint available at: Linköping University Electronic Press

http://urn.kb.se/resolve?urn=urn:nbn:se:liu:diva-71752 


\title{
Exploring the Characteristics of Information Systems Maintenance - Defining Focus and Content through Objects
}

\author{
Malin Nordström ${ }^{1}$, Karin Axelsson ${ }^{1}$ and Ulf Melin ${ }^{1}$ \\ ${ }^{1}$ Linköping University, Department of Management and Engineering, SE-581 83 \\ Linköping, Sweden \\ \{malin.nordstrom, karin.axelsson, ulf.melin\}@liu.se
}

\begin{abstract}
The purpose of this paper is to explore the characteristics of information systems (IS) maintenance within an IT and organizational setting. We discuss the characteristics of maintenance objects' focus and content. Our results are based on qualitative case studies. In this paper a case study of a Swedish Bank is used to illustrate our discussion. Our findings show that maintenance objects can be defined by processes and/or functions or products and/or services within an organizational setting. This is done in order to increase a business perspective in maintenance management and to clarify roles of responsibility for organizational changes required from new IT capabilities. According to our findings maintenance objects can contain business solutions and IT solutions. This implies that business beneficial maintenance is supported by close cooperation between actors from the organizational setting and the IT organization. The result of the paper is a characterization of IS maintenance through definition of maintenance objects' focus and content.
\end{abstract}

Keywords: IS maintenance, IS maintenance management, Maintenance objects, Information systems.

\section{Introduction}

Increasing demands from customers or other clients regarding, for example, cost reductions, high quality and value for money (ROI), imply among other things that information systems (IS) maintenance organizations need to be more effective. Higher functionality and stability in the IT solution portfolio, and overall quality in core business, and at the same time lower IS maintenance costs is an equation that is often difficult to solve. To meet the increasing demands, maintenance organizations have to deal with the ability to further develop and maintain IS. This is not an easy task and requires an adequate management system, which has to satisfy a number of not always homogenous needs [1]. Some twenty years ago, Colter [9] stated that the greatest problem of software maintenance is of managerial nature rather than technical. Sneed and Brössler [28] developed this argument further by identifying success factors for software maintenance, and they mean that success in maintenance 
can not only be measured by cost reduction and user satisfaction - this is an oversimplification of a far more complex issue (ibid.).

Definitions of system maintenance often stress the post-delivery characteristics and define system maintenance to be different types of changes [16]. In these definitions management is seen as part of the change activities. This kind of categorizations of changes originates from Lientz' and Swanson's dissertation in 1980 [19], but has been further developed by many researchers and practitioners since then [7]. Measurements indicate that most of the change activities aim to improve and adapt IS to changed environments. Researchers therefore mean that "maintenance" is too narrow as a concept and prefer the concept "evolution" (ibid). Their point is that maintenance is associated with corrective activities, rather than further development. Another dimension of the definition of maintenance is that the concept has been criticized as being too narrow because of its delimited substance of change activities. Researchers also seem to agree that system maintenance is quite unfairly treated and therefore underexplored, in theory and practice, in relation to its importance for organizations (ibid).

The most recommended means of control for maintenance is management by actions or management by contracts. The most common way to control this is maintenance process management and service level agreements (SLA). SLA's often contain agreements concerning availability, opening hours and response time. The lack of common processes for specific maintenance activities is often pointed out as an explanation to ad-hoc maintenance management [1]. Another common means of control is management by objectives, but we have not found much literature about managing maintenance by business objectives. We actually find this quite strange, because in a maintenance situation there is an opportunity to measure the benefit of IT investments, benefits that are often more or less well defined in business cases that have preceded IT investments. A possible explanation for this is that maintenance often is performed from an IT perspective (a more narrow technology focus) which puts the business perspective in the background. This kind of more isolated IS maintenance does not normally admit management by business objectives because the business objectives are not known by the maintainers. The two roles that are outlined in literature representing businesses are user and customer [1; 17], but none of these roles are members of a maintenance organization. Instead, they are expected to formulate their needs in a request for change or equivalent (ibid).

IT focused maintenance, based on a technological focus, as described above, can over time mean that the IS no longer supports the current organizational needs because the relations between IT maintenance organizations and customers and users are not clarified [22]. Time is an important factor for this situation. Organizational settings change over time and it is also common that IS are used for new business processes different from the original purpose (ibid). Thus, in this paper we argue that the business perspective in maintenance management must become more explicit.

The maintenance management challenge is well known by both researchers and practitioners, but practitioners are still - in many settings - struggling with the management problem. Since there are other resources that are maintained as well, such as buildings and stock portfolios, it is reasonable to assume that the characteristics of the maintenance object are important for management. The purpose of this paper is to explore the characteristics of IS maintenance within an IT and 
organizational setting. We discuss the characteristics of maintenance objects' focus and content. Our idea is to use the maintenance object to organize maintenance management and thereby clarify maintenance assignments. The research questions in the present paper are; (1) how can maintenance objects be focused and (2) what will the objects contain?

The paper is organized as follows. After this introduction we identify some important theoretical points of departure for the study in section 2, and in section 3 the research design is presented. Section 4 describes the case study at a Swedish Bank. In section 5 we analyze our empirical data. Finally, in section 6 our conclusions and ideas for further research are presented.

\section{Theoretical Points of Departure}

In this section we describe and discuss some theoretical statements that we used as theoretical points of departure when we carried out the case study presented below.

\subsection{IT Systems Creating Benefits within Organizations}

In the IS field the concept "information system" originally was defined as encompassing both computerized information processing and manual information processing $[8 ; 13 ; 18]$. Thus, theoretically the IS concept is wider than computerized information processing (e.g. as typically defined in the computer science discipline [cf. 29]), but in practice IS is often interpreted as a system for computerized information processing. To clarify the distinction between what is computerized or not we choose to use other concepts; IT system is used for the computerized information processing and organizational setting for activities that are performed with or without the aid of IT systems. We also use the terms process and function for subsets in an organizational setting.

Niessink and van Vliet [21] introduce a service perspective on maintenance and argue for a difference between development and maintenance in the light of products and services. They mean that while the result of a development activity is a product, the result of a maintenance activity is a service. But at the same time they mention that the differences between products and services are not clear in the marketing literature (ibid.). The starting point for their argument is the IT organization which has to fulfill the needs of software for current businesses in order to create business value and benefits of IT.

Statements concerning IT systems and organizational settings also influence the content of maintenance objects. There is a difference between maintaining the IT system or maintaining the IT system and the organizational setting. Several authors argue for the intertwined nature of IS in action and organizational settings [e.g., 23; 24; 29], sometimes with inspiration from symbolic interactions [6]. Maintaining the IT system and the organizational setting is obviously not reasonable as an assignment for a maintenance organization, as it would mean that the maintenance organization is responsible for the organizational setting. However, establishing the boundary is not as easy as it seems because at the same time as the maintenance organization 
maintains an IT system it also maintains a computerized organizational setting embedded in the IT system. This implies that IT systems are an intertwined part of organizational settings and have socio-material dimensions [23; 24; 29]. This also implies that IT systems are supporting actions in organizational settings [8; 15; 32]. With an increasing use of IT systems, more and more in the organizational setting is maintained by maintenance organizations. This situation may lead to unclear roles of responsibility between maintenance organizations and organizations or parts of organizations that perform the current business tasks in the organization.

In the IS field, it is also common to initially perform a business analysis before development or change of IT systems [2]. This also goes for other change attempts such as Total Quality Management (TQM) [12]. In TQM evaluations of business processes are a part of an ongoing process of continuous improvement. In software maintenance theory there is no such evident tradition, which may partly be explained by the development of system maintenance theory in the Software Engineering area where the IS is seen as a product rather than an integrated part of the business, in line with the perspective outline above. An early study that stressed the importance of a business perspective was Bendifallah and Scacchi [4]. They conducted a study of IT system maintenance from a user perspective and thereby studied the organizational setting and how it interacts with the IT systems. Their conclusion was that in order to understand the system maintenance, one must understand the surrounding organizational setting and the users' and the maintainers' situation (ibid). More recent studies have stressed the maintenance practice [27; 28], but only a few have emphasized the importance of a clarified business perspective. The organizational setting that the IT system supports is, thus, implicit in much research.

A maintenance organization without a maintenance object is quite meaningless, but in software maintenance research the object's focus and content are treated rather unreflecting and are not investigated thoroughly. Concepts such as software, systems or products are used frequently but are not analyzed any further. Kitchenham et al. [17 p. 370] talk, e.g., about the maintained object in terms of "the software application, product or package that is undergoing modification. A product is a conglomerate of a number of different artifacts". Further, they discuss how the product is influenced by domains, age, maturity composition, and quality (ibid.).

\subsection{Organizing Maintenance Settings}

As mentioned above, an organizational setting perspective highlights what is done, with or without IT systems, and the need to focus IT as an integrated part of an organization. IT systems are related to activities performed in the organizational setting rather than to the organization per se. Maintenance is complex with many internal and external parties involved, which makes it necessary to distinguish between activities performed in the organizational setting and the organization. Otherwise there is a risk that maintenance still lacks influence from a business perspective. In order to analyze system maintenance we have redefined the concept through different sub categories. The two main concepts are organizational setting and IT setting, which is a consequence of our intention to increase the business perspective in maintenance management theory. Organizational setting is a generic 
concept and includes any kind of activities, thus, system maintenance is conducted in all kinds of organizations that use IT systems. By IT setting we mean the technically oriented work that is carried out to handle IT systems. Based on the understanding of IT as a natural and intertwined part of an organizational setting [23; 24; 29] we also view systems maintenance as including organizational processes and/or functions and IT. We illustrate maintenance as a subset of both the organizational setting and the IT setting (figure 1).

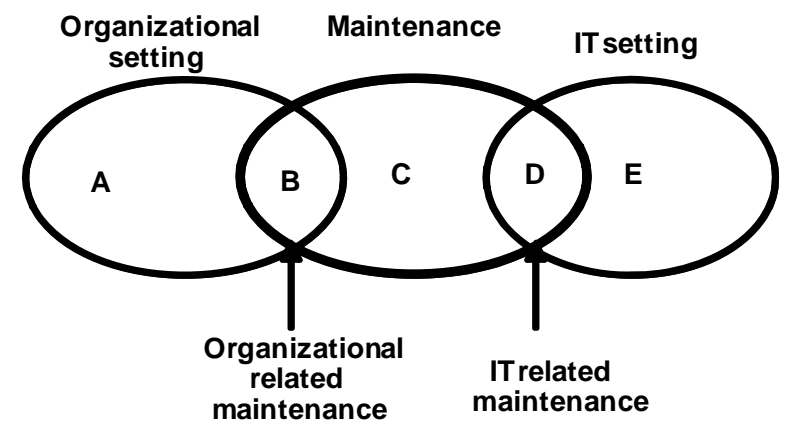

Figure 1. Maintenance as a subset of the organizational setting and the IT setting.

The perspective of maintenance as a subset of the organizational setting and the IT setting results in two sub-categories of maintenance; organizational related maintenance (field B in figure 1) and IT related maintenance (field D in figure 1). Field $\mathrm{C}$ is formed by a common management of field $\mathrm{B}$ and $\mathrm{D}$ that arises since maintenance is a subset of the organizational setting and the IT setting. The activity is of a managing character (i.e., giving and taking assignments).

Nordström and Welander [22] argue for a high influence from the current organizational setting in a maintenance organization in order to increase the benefit of IT systems over time.

\section{Research Design}

The results presented in this paper originate from a research project with a wider scope containing three case studies (a Swedish Bank, a Telecom Company and a Swedish Authority). In this paper we explore the focus and content of maintenance objects within the Swedish Bank's domestic and international payments. The studied maintenance objects have, in the research project, been used as means to organize maintenance activities. The research project has been performed with a pragmatic perspective. We agree with Wicks and Freeman [31] as well as Cronen [10] that a pragmatic view allows the researcher to see the value of theories as an aid to predict phenomenon, and also manages people's actions in order to improve organizational settings. Within a pragmatic approach, practical use of research findings is highly valued, and therefore we have chosen a qualitative interpreting research approach. Interpretive research, within the IS discipline, concentrates on creating an 
understanding for the IT system in context [e.g., 29]. The researchers are therefore interested in how IT systems are influenced by the context, and how IT systems influence the organizational setting [20; 30]. Qualitative case studies have been used in the present research project combined with an action research (AR) approach. AR is often used in the IS discipline [3]. The purpose of AR is to improve the studied object at the same time as scientific knowledge is developed (ibid.). The empirical data has been analyzed following a qualitative, interpreting approach [30].

The case study at the Swedish Bank contained three phases; object inventory, object modeling, and proposal for organizing the maintenance practice. Phase 1 and 2 are focused in this paper. Phase 1 - the object inventory - started with a definition of the organizational setting to make it understandable to the researchers. The information was collected by interviews with 20 key persons. The key persons had roles of responsibility for payment products, market segments, sales channels, payment processes or IT systems. The interviews were documented and resulted in lists of payment products, market segments, sales channel, payment processes, and IT systems and their relations. In this phase we discussed the maintenance objects during a workshop with key actors from the Bank. In the last phase we made a proposal for organizing maintenance according to Nordström and Welander [22].

\section{Payments at the Bank - Findings from a Case Study}

The researchers got the AR assignment to reorganize maintenance practice at the Bank in order to use the IT systems in a more effective way. The maintenance practice was fragmented with highly delegated responsibilities, which led to a lack of a holistic view and ineffective use of resources. The maintenance practice was also characterized by a high level of key person dependence. Producers of the payments were the Department of Private and Commercial Payments with approximately 150 employees. The payment practice was divided into four subsets:

- Payment production

- Product development and maintenance

- IT development, maintenance and production

- Marketing

The range of products consisted of approximately 40 payment products, for example corporate payments, private payment and bank-to-bank payments. The main clients were Bank clients via their own bank. The products were accessible via sales channels such as the phone, web, ATM, and bank office. There were also approximately 40 IT systems which primarily supported the payment process. The maintenance was organized with the help of seven maintenance objects in which IT systems were grouped together. The underlying ground for the grouping of IT systems showed signs of:

- Organizational boundaries

- Design of IT systems 
- Personnel extent

- Dependence of key persons

With the result from the object inventory the IT systems were analyzed from the view of process, products, sales channels, and market segments. Together with key persons from the payment department we then discussed the consequences of the different object grounds. During the test we found out that a combination of a product and/or service and process and/or function view was the most effective way to group IT systems in order to create clarified maintenance assignments. The organizational grouping was rejected because of constant reorganizing of the line organization, and because the complexity of internal and external parties. The IT system design grouping was rejected because of its volume and because of the lack of business perspective. When we used the process and/or function or product and/or service perspective we found out that we avoided the above mentioned problems. But because of the IT systems multi-functional nature we sometimes had IT systems that supported several processes and/or functions. However, no attempt to share IT systems between objects was done. We used the dominance principle and in borderline cases the IT system was placed into the object in which organizational setting it was primarily used. Together with the participants from the Bank we formed three maintenance objects; Payments, Warehouse, and Clearing.

The first, and most extensive, was Payments. In that object we brought together every payment IT system regardless of whether they supported domestic or international payment products, and independent of which market segment the payment product belonged to. This was done as a difference to the existing maintenance objects in which domestic and international payments and market segments were separated. The object Warehouse contained IT systems supporting complementary products to payments, such as autogiro and BankID. The object Clearing was performed independently of the current product and therefore we chose to put it in a separate object. The participants from the Bank thought that this new object structure, with new bounds of responsibility, gave them the opportunity to;

- Clarify maintenance assignments

- Eliminate competition between products and IT systems

- Decommission non-profitable products and their IT systems

- Merge domestic and international payment products

- Differentiate between products and IT systems

- Use IT systems and employees in a more effective way

With the wider scope and with a clarified business perspective, it became obvious for the maintainers at the Bank that they are maintaining something more than only a technical IT system. Only a few matters of their daily work concern the IT systems from a technical point of view. Together with the participants we started to talk about Business Solutions as the organizational setting view of an IT system and IT Solution as the technical view of an IT system. We found out that a Business Solution may contain IT functions, documents and added value from the maintenance organization. We created for example a Business Solution for Knowledge Support containing computerized help instructions together with paper based guidelines. The added value 
from the maintenance organization was to adapt them to the target group. The findings of Business Solutions as a part of the maintenance object gave the Bank the opportunity to clarify roles of responsibility for the organizational setting perspective of the IT system. Later they also pointed out roles of responsibility and documented clarified maintenance assignments with the maintenance object as a starting point.

\section{Characteristics of IS Maintenance}

In this section we relate our empirical findings from the Bank study to our theoretical statements presented earlier in the paper.

\subsection{Maintenance Objects’ Focus}

Our first research question was related to the focus of maintenance objects. The case study at the Bank showed us the possibility of focusing maintenance objects within a products and/or services or process and/or function view. Together with the action perspective on IT systems [14; 15; 32], which states that IT systems perform actions in organizational settings, and the results from the case study, our conclusion is that maintenance objects should be focused by products and/or services (Payments and Warehouse at the Bank) or process and/or functions (Clearing at the Bank). Organizational boundaries were rejected as a focus definer because of constant reorganization in the line organization. From a theoretical view organization is not a good focus definer either, because IT systems have relations to actions performed in the organizational setting rather than to the organization itself. However, in a situation where IT systems are used by different internal and even external parties it is necessary to clarify the difference between actions in the organizational setting and the organization. Otherwise it is possible that maintenance organizations are only manned from an organizational view and the maintenance still lacks business perspectives and objectives.

In the case study at the Bank we had no discussions about the extent of the maintenance objects or sharing of IT systems between maintenance objects because of their multi-functionality from an organizational setting view. However, this could be an issue in situations with large maintenance objects, but maybe foremost from a theoretical view. Even our most extended maintenance object at the Bank - Payments - did not trigger any extent discussions. In the Bank study there were no problems with IT systems that supported several products and/or services. However, the extent of maintenance objects and also multi-functional IT systems are factors to take into consideration when defining the focus of maintenance objects.

To summarize, we suggest four factors to take into consideration when defining the focus of maintenance objects;

- Work practice products and services

- Product independent processes

- The extent of the maintenance objects

- Multi-functional IT systems 


\subsection{Maintenance Objects' Content}

Our second research question concerned the content of maintenance objects. Our results are based on the action perspective of IS, where IT systems have an organizational dimension as well as a technical one (as stated above). In the case study at the Bank we started to name the organizational setting dimension "Business Solution" and the technical dimension "IT Solution". In order to increase the organizational setting dimension and to clarify business objectives and roles of responsibility, our conclusion therefore is that a maintenance object should contain Business Solutions and IT Solutions. Together they are used in an organizational setting to produce products and/or services. In figure 2 below, we have further developed figure 1 by adding Business Solutions and IT Solutions.

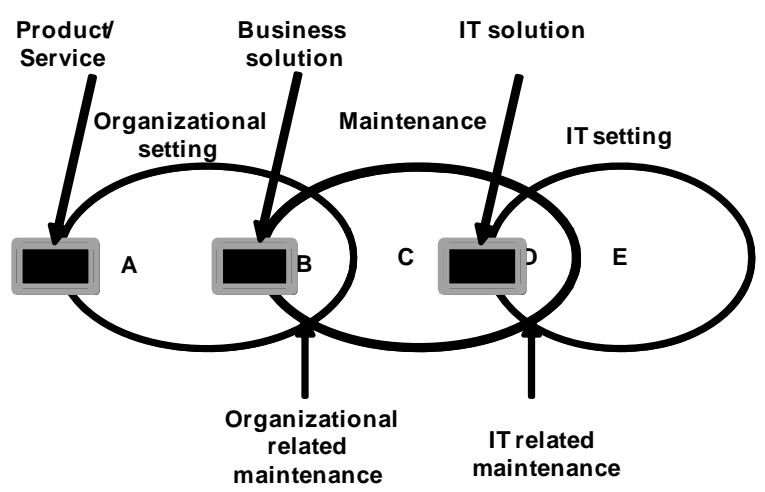

Figure 2. Maintenance objects' content.

This resulted in the following discussion: An IT solution is the maintenance object for IT related maintenance (field D) which is performed by internal or external IT suppliers. The IT Solution is also the delivery of the IT related maintenance to the organizational related maintenance (field B). Organizational related maintenance is performed by parties who are involved in current actions in the organizational setting. At the Bank it was persons working with or responsible for payments. Organizational setting maintenance has Business Solutions as their maintenance objects which also are their delivery to parties who perform current actions in the organizational setting (field A). This means that we adopt a service perspective on maintenance. In line with Niessink and van Vliet [21] we want to use the service perspective to create clarified maintenance assignments, but with this statement we go beyond their conclusion, as we combine a service and a product perspective.

With a wider scope of maintenance objects it was also possible for the maintainers at the Bank to take the responsibility for described business processes (payments) and not only for computerized functions. This observation was the starting point for defining Business Solutions as a part of the maintenance objects. A maintenance organization may have the responsibility for computerized work but also for the organizational setting. However, is it not reasonable to take responsibility for the current organizational setting itself? In the case study at the Bank we showed that this is possible with an action perspective on IT systems [14; 15; 32]. 
IT Solutions contain one or more IT systems or other technical components. Based on the results from the case study at the Bank our conclusion is that Business Solutions contain the following components;

- IT system functions and/or processes

- Described processes and/or functions

- Added value from the maintenance organization

\section{Conclusions}

In this paper we have analyzed and discussed focus and content of maintenance objects containing IT systems. Field observations related to the consequences of isolated IT system maintenance were the background to the research project. We investigated approaches to increase the business perspective in maintenance work as a way of tackling the management problem in maintenance. Our two research questions concerned focus and content of maintenance objects, which can be used as a starting point to create clarified assignments for maintenance.

Our first conclusion is that maintenance objects could be focused by products and/or services or processes and/or functions in order to increase the business perspective in maintenance. Multi-functional IT systems and the extent of maintenance objects must also be taken into consideration when defining focus for maintenance objects. Our second conclusion is that maintenance objects could contain business solutions and IT solutions to take the organizational setting perspective and the IT system perspective simultaneously into consideration. This means that a business solution can contain a business process with its IT functionality. A business solution also gives the opportunity to clarify roles of responsibility for changes in the organizational setting required by new IT capabilities. The conclusions of the content and focus of maintenance objects lead us to a view where we think it is fruitful to stop talking about maintenance as a technical phenomenon only, and include the organizational setting dimension. These findings are in line with, e.g., Sillito and Wynn [27] whose understanding is that maintenance work is highly context dependent. The complement of maintenance objects containing Business Solutions as well as IT Solutions also means that it is necessary for representatives from the organizational setting to be a part of the maintenance organization. It is not enough to categorize them as customers or users; they must be more thoroughly involved. We argue that it is necessary that persons from the current organizational setting must be permanent members of maintenance organizations in order to improve or guarantee the organizational setting perspective over time.

The results presented in this paper should not be seen as final - rather explorative and emerging results that need to be further validated, investigated and developed in line with a cumulative research tradition. As mentioned above, our conclusions are based on three case studies - one of the cases focused and illustrated in this paper. The results from the studies are similar - a clear pattern appears. We have therefore only presented the case study at the Bank in this paper, but we still need to add more empirical data. However, we find the results interesting enough to be developed 
further and the case studies have strengthened our idea of the need for an increasing business influence in maintenance activities. To further develop the findings concerning maintenance objects we plan to investigate the relations between maintenance objects. We have developed a framework which aims to describe an organization's collected quantity of maintenance objects in a maintenance object architecture (MOA). Our idea is that the MOA can be used to improve IT governance for maintenance, in the same way as Enterprise Architecture is used to improve IT governance for strategic IT decisions [5; 25]. The MOA will give organizations an overview of the total portfolio of maintenance objects. By using our view of IT systems from an organizational setting context we hope that MOA can be a basis from which the gap between business staff and IT staff can be bridged, which is one of the aims of an IT governance framework [cf. 11; 26].

\section{References}

1. April, A., Huffman Hayes, J., Abran, A and Dumke, R., 2005. Software Maintenance Maturity Model (SMMmm): the software maintenance process model. Journal of Software Maintenance and Evolution: Research and Practice, No. 17, pp 197-223

2. Avison, D.E. and Fitzgerald, G., 1998. Information Systems Development: Methodologies, Techniques and Tools. 3 rd Edition. McGraw-Hill, London

3. Baskerville, R. and Myers, M.D., 2004. Making IS research relevant to practice Foreword, MIS Quarterly Special issue on action research in information systems, Vol. 28, No. 3, pp 329-335

4. Bendifallah, S. and Scacchi, W., 1987. Understanding software maintenance work. IEEE Transactions on software engineering, Vol. 13, No. 3, pp 311-323

5. Bernard, S.A., 2005. An introduction to enterprise architecture. Bloomington, IN

6. Blumer, H., 1969. Symbolic Interactionism: Perspective and method. University of California Press, Barkley

7. Chapin, N., Hale J.E., Khan, K.M., Ramil, J.F. and Tan, W-G., 2001. Types of software evolution and software maintenance. Journal of Software Maintenance and Evolution: Research and Practice, 13(1), pp 3-30

8. Checkland, P. and Holwell (1998). Information, Systems and Information Systems making sense of the field, Wiley \& Sons., Chichester

9. Colter, M.A., 1987. The business of software maintenance. In Proceedings of the $1^{\text {st }}$ European Workshop of Software Maintenance. Computer Science Department, University of Durham, Durham, U.K, pp. 12

10. Cronen, V., 2001. Practical Theory, Practical Art, and the Pragmatic-Systemic Account of Inquiry. Communication Theory, 11(1), pp 14-35

11. de Haes, S. and van Grembergen, W., 2004. IT Governance and its mechanisms. Information Systems Control Journal, Vol. 1

12. Deming, W.E., 1982. Out of the Crisis. Massachusetts Institute of Technology, Center for Advanced Educational Services, Cambridge, Massachusetts

13. Galliers, R. (2003). Change as Crisis or Growth? Toward a Trans-disciplinary View of Information Systems as a Field of Study: A Response to Benbasat and Zmud's Call for Returning to the IT Artifact. Journal of the Association for Information Systems, 4(6), pp 337-351

14. Goldkuhl, G. And Lyytinen, K. 1982. A language action view of information systems, Proceeedings of the $3^{\text {rd }}$ International Conference on Information Systems, Ann Arbor, pp 13-30. 
15. Goldkuhl, G. and Ågerfalk, P. J., 2005. IT Artefacts as Socio-Pragmatic Instruments: Reconciling the Pragmatic, Social, Semiotic and Technical, International Journal of Technology and Human Interaction. 1(3), pp 2341-2354

16. IEEE., 1998. Standard for Software Maintenance, IEEE Std 1219-1998. The Institute of Electrical and Electronics Engineers Inc.

17. Kitchenham, B.A., Travassos, G.H., von Mayrhauser, A., Niessink, F., Schneidewind, N.F., Singer, J., Takada, S., Vehvilainen, R. and Yang, H., 1999. Towards an Ontology of Software Maintenance. Journal of Software Maintenance and Evolution: Research and Practice, No. 11, pp 365-389

18. Langefors, B., 1966. Theoretical Analysis of Information Systems. Studentlitteratur, Lund

19. Lientz, B. and Swanson, E.B., 1980. Software Maintenance Management. Addison- Wesley Publishing, Reading MA

20. Myers, M.D. and Avison, D.E., 2002. An Introduction to Qualitative Research in Information Systems, in Myers, M.D. och Avision, D.E. (editor). Qualitative Research in Information Systems - A Reader, Sage Publications Ltd, London, pp 3-12

21. Niessink, F. and van Vliet, H., 2000. Software maintenance from a service perspective. Journal of Software Maintenance and Evolution: Research and Practice, No. 12, pp 103120

22. Nordström, M. and Welander, T., 2005. Business Oriented Systems Maintenance Management, in Khan, K. and Zhang, Y (eds), Managing Corporate Information Systems Evolution and Maintenance, Idea Group Publishing, Hershey PA, pp 326-344

23. Orlikowski, W.J., 2007. Sociomaterial Practices: Exploring Technology at Work, Organization Studies, 28(9), pp 1435-1448

24. Orlikowski, W.J. and Scott, S.V., 2008 Sociomateriality: Challenging the Separation of Technology, Work and Organization, The Academy of Managements Annals, 2(1), pp 433474

25. Ross, J.W., Weill, P. and Robertson, D.C., 2006. Enterprise Architecture as Strategy. Harvard Business School Press, Boston, Massachusetts

26. Schwertsik, A., Wolf, P. and Krcmar, H., 2009. IT-controlling in federal organizations. In Newell, S., Whitley, E., Pouloudi, N., Wareham, J. and Mathiassenl, L. (Eds., 2009), Proceeding of the 17th European Conference on Information Systems (ECIS2009), Verona, Italy, 8-10 June 2009, pp 2158-2169

27. Sillito, J. and Wynn, E., 2007. The Social Context of Software Maintenance. In Proceedings of the International Conference of Software Maintenance, pp 325-334. IEEE Computer Society, Paris

28. Sneed, H. and Brössler, P., 2003. Critical Success Factors in Software Maintenance A Case Study. In Proceedings of the International Conference on Software Maintenance, pp. 190. IEEE Computer Society, Amsterdam

29. Walsham, G., 1993. Interpreting Information Systems in Organizations, Wiley \& Sons., Chichester

30. Walsham, G., 2006. Doing interpretive research. European Journal of Information Systems, 15(3), pp 320-330

31. Wicks, A.C. and Freeman, R.E., 1998. Organization Studies and the New Pragmatism: Positivism, Anti-positivism, and the Search for Ethics. Organization Science, Institute for Operations Research and the Management Sciences, 9(2), pp 123-140

32. Winograd, T. and Flores, F., 1986. Understanding computers and cognition: A new foundation for design, Ablex, Norwood 